\title{
A polymorphism near IGF1 is associated with body composition and muscle function in women from the Health, Aging, and Body Composition Study
}

\author{
Matthew C. Kostek • Joseph M. Devaney • Heather Gordish-Dressman • Tamara B. Harris • \\ Paul D. Thompson • Priscilla M. Clarkson • Theodore J. Angelopoulos • Paul M. Gordon • Niall M. Moyna \\ Linda S. Pescatello $\cdot$ Paul S. Visich $\cdot$ Robert F. Zoeller $\cdot$ Richard L. Seip • Melissa Garcia • \\ Rongling Li · Joseph M. Zmuda • Matthew J. Delmonico • Alka Kanaya • Eric P. Hoffman
}

Accepted: 29 April 2010/Published online: 19 May 2010

(C) The Author(s) 2010. This article is published with open access at Springerlink.com

\begin{abstract}
Previous studies have reported associations of polymorphisms in the IGFI gene with phenotypes of body composition (BC). The purpose of this study was to identify phenotypes of $\mathrm{BC}$ and physical function that were associated with the IGF1 promoter polymorphism (rs35767, $-\mathrm{C} 1245 \mathrm{~T})$. Subjects from the Health, Aging, and Body Composition Study, white males and females $(n=925 / 836)$ and black males and females (533/705) aged 70-79 years were genotyped for the polymorphism. Phenotypes of
\end{abstract}

Communicated by Susan Ward.

Electronic supplementary material The online version of this article (doi:10.1007/s00421-010-1500-0) contains supplementary material, which is available to authorized users.

\section{C. Kostek}

Department of Exercise Science, University of South Carolina, Columbia, SC, USA

J. M. Devaney · H. Gordish-Dressman · E. P. Hoffman ( $\square)$ Research Center for Genetic Medicine, Children's National Medical Center, Washington, DC, USA

e-mail: ericphoffman@gmail.com

T. B. Harris - M. Garcia

National Institute of Aging, National Institutes of Health, Bethesda, MD, USA

P. D. Thompson · R. L. Seip

Division of Cardiology, Henry Low Heart Center,

Hartford Hospital, Hartford, CT, USA

\section{P. M. Clarkson}

Department of Kinesiology, Totman Building,

University of Massachusetts, Amherst, MA, USA

T. J. Angelopoulos

Center for Lifestyle Medicine, University of Central Florida,

Orlando, FL, USA muscle size and function, bone mineral density, and BC were analyzed for associations with this polymorphism. To validate and compare these findings, a cohort of young (mean age $=24.6, \mathrm{SD}=5.9$ ) white men and women ( $n=173 / 296)$ with similar phenotypic measurements were genotyped. An association with BC was identified in elderly females when significant covariates (physical activity, age, smoking status, body mass index) were included. White women with $\mathrm{C} / \mathrm{C}$ genotype had 3\% more trunk fat and $2 \%$ more total fat than those with $\mathrm{C} / \mathrm{T}(P<0.05)$. Black women with $\mathrm{C} / \mathrm{C}$ genotype had 3\% less total lean mass and 3\% less muscle mass than their T/T counterparts $(P<0.05)$. Associations were identified with muscle strength in white women $(P<0.01)$ that were in agreement with the $\mathrm{C} / \mathrm{C}$

P. M. Gordon

Department of Physical Medicine and Rehabilitation,

University of Michigan, Ann Arbor, MI, USA

N. M. Moyna

Department of Sport Science and Health, Dublin City University,

Dublin, Ireland

L. S. Pescatello

Department of Kinesiology, School of Education,

University of Connecticut, Storrs, CT, USA

\section{P. S. Visich}

Human Performance Laboratory, Central Michigan University, Mount Pleasant, MI, USA

R. F. Zoeller

Department of Exercise Science and Health Promotion,

Florida Atlantic University, Davie, FL, USA

R. Li

Department of Preventive Medicine, University of Tennessee, Memphis, TN, USA 
genotype having lower muscle function. Thus, in an elderly population but not a young population, a polymorphism in the IGFI gene may be predictive of differences in body composition, primarily in black females.

Keywords IGF1 - Muscle - Body composition . Bone mineral density $\cdot$ Elderly $\cdot$ SNP

\section{Introduction}

IGF1 is known to be necessary and sufficient in promoting muscle growth and development (Coleman et al. 1995; Powell-Braxton et al. 1993; Gonzalez et al. 2003; Greig et al. 2006; Bamman et al. 2007). In the search for genomic regions that regulate muscle growth and repair over the human life span, genome wide association studies are often employed. The few studies that have examined muscle function as a variable have found that a region near $I G F I$ on chromosome 12 appears to be one of the most influential (Sun et al. 1999; Chagnon et al. 2001). This region, in the vicinity of the promoter of IGFI has been studied extensively and seems likely to play a role in at least circulating IGF1 levels (Frayling et al. 2002; Rietveld et al. 2003; Rosen et al. 1998), though not all studies agree with these results (Missmer et al. 2002; Kim et al. 2002). Only two studies have examined a polymorphism in this region specifically as it relates to muscle strength in humans, and in both cases the elderly. While an association was found the functionality of that polymorphism is currently unknown (Kostek et al. 2005; Hand et al. 2007). Due to the nature of a dinucleotide repeat (CA) such as the aforementioned, haplotypes will be difficult to establish; thus there is a need to study SNPs in this region to identify associations before haplotypes can be examined.

Recently, other polymorphisms in the promoter region of IGF1 have gained attention (Cheng et al. 2006; Canzian et al. 2006; Tamimi et al. 2007; Hernandez et al. 2007). Two studies examining prostate cancer risk in either a multiethnic cohort or an African-American population demonstrate that the rs7965399 SNP is associated with cancer risk and circulating levels of IGF1(Cheng et al. 2006; Hernandez et al. 2007). Additionally, in the Nurses' Health Study an

\section{J. M. Zmuda}

Department of Human Genetics, University of Pittsburgh, Pittsburgh, PA, USA

\section{J. Delmonico}

Department of Kinesiology, University of Rhode Island,

Kingston, RI, USA

A. Kanaya

Division of General Internal Medicine, University of California-

San Francisco, San Francisco, CA, USA association was found between rs35767 IGF 1 promoter SNP and mammographic density, which is relevant because mammographic density is known to be under partial control of IGF1 levels (Tamimi et al. 2007). In the EPIC study of breast cancer, the rs $35767 \mathrm{SNP}$ in the promoter of $I G F 1$ was associated with blood levels of IGF1 and breast cancer risk (Canzian et al. 2006). In terms of muscle function, our preliminary analysis suggested that the rs 35767 was associated with skeletal muscle phenotypes in a younger (1834 years) population, yet the sample size was small and a validation cohort was not available at the time of the study (Devaney et al. 2004). With the known decrease of IGF1 levels with increasing age and impact of IGF1 on measures of $\mathrm{BC}$ and muscle function, we sought to examine the association of this SNP with BC in an older population and to reanalyze our younger population using the entire Caucasian cohort. The rationale being that if IGF1 genotype were predictive of $\mathrm{BC}$ changes with aging that were detrimental to health, early intervention programs could be more efficiently targeted in these individuals. If the $\mathrm{BC} /$ genotype associations were present at an early adult age, interventions could begin early but if the associations were only present in the elderly it would need to be determined when in the aging process these associations become relevant. We hypothesized that an association would exist in phenotypes known to be controlled by $I G F 1$.

\section{Methods}

The current study analyzed data from two separate prospective studies, Health, Aging, and Body Composition (Health $\mathrm{ABC}$ ), and Functional SNPs associated with human Muscle Size and strength (FMS). The Health ABC study recruited 3,075 participants from the Pittsburgh, PA and Memphis, TN metropolitan areas. Participants were men and women between the ages of 70-79 years of whom $48.4 \%$ were women and $41.7 \%$ black. Participants selfreported having no difficulty walking $1 / 4$ mile, climbing 10 stairs, or performing basic activities of daily living. All participants were free of life-threatening illness and did not plan to move from the area for at least 3 years. The study protocol was approved by the Institutional Review Boards of the University of Tennessee, Memphis and the University of Pittsburgh, and each participant provided written informed consent for participation.

Health ABC

\section{Body composition}

Body weight and height were measured without shoes in a hospital gown on a calibrated balance-beam scale and 
stadiometer. BMI was calculated as $\mathrm{kg}$ of body weight/ height in $\mathrm{m}^{2}$. Lean total body mass was assessed using DEXA (Hologic QDR 4500 software version 8.21). Total lean mass was defined as measured lean mass plus bone mineral content (Visser et al. 1999). Trunk fat and appendicular fat were determined as previously described (Visser et al. 2003). Total body fat mass and percent body fat were also measured (Park et al. 2006).

\section{Strength assessments}

All strength measures have been reported previously (Park et al. 2006). Briefly, knee extension strength was measured using an isokinetic dynamometer (125 AP; Kin-Com, Chattanooga, TN) and an isometric dynamometer was used (Jaymar; JLW Instruments, Chicago, IL) for grip strength. For knee extension, maximal voluntary concentric isokinetic torque was assessed at an angular velocity of $60^{\circ} \mathrm{s}^{-1}$. At least three, but no more than six, maximal efforts were allowed and the mean maximal torque was recorded and used for the analysis. Isometric grip strength was assessed for each hand. The vast majority (96\%) who had leg strength testing also had grip strength testing. For these analyses, we used the maximum of the force from two trials for the right upper extremity.

\section{$C T$}

Skeletal muscle composition assessed via CT (9800 Advantage, General Electric, Milwaukee, WI, Somatom Plus 4, Siemens, Erlangen, Germany and PQ 2000S, Marconi Medical Systems, Cleveland, $\mathrm{OH}$ ) has been described previously (Goodpaster et al. 2001). Briefly, to localize the mid-thigh position, a scout scan was obtained. The scan position was determined as the midpoint of the distance between the medial edge of the greater trochanter and the intercondyloid fossa of the right leg. A single $10-\mathrm{mm}$ slice (120 kVp and 200-250 mA) was obtained at the femoral midpoint. All images were analyzed by a single observer. Proprietary software using the IDL development platform (RSI Systems, Boulder, CO) was utilized to calculate skeletal muscle and area of the thigh. Subcutaneous adipose tissue area was distinguished from intermuscular adipose tissue area by manually drawing a line along the deep fascial plane surrounding the thigh muscles. Once the adipose tissue was identified, the individual muscles were measured utilizing manual tracing. The total area of nonadipose, nonbone tissue within the deep fascial plane was used as a measure of muscle area.

\section{Physical function}

Physical function as related to muscle strength was determined from the Health ABC physical function test battery utilizing two tests, which have been described in detail previously (Taaffe et al. 2000). Briefly, the test battery is an extension of the lower-extremity performance tests used in the Epidemiologic Studies of the Elderly (EPESE) (Brach et al. 2004) and includes five repeated chair stands and gait speed assessment. Gait speed was assessed over a 20-m straight course (Atkinson et al. 2007).

\section{FMS}

Details of the FMS population have been previously reported (Thompson et al. 2004). Briefly, FMS was a multicenter prospective study to examine associations of muscle size and function with genotype. Subjects were recruited to participate in a progressive resistance training program lasting 12 weeks. Each subject had MRIs of the upper arms to analyze muscle, bone, and fat. All measures were collected at baseline and the data were utilized in the current cross-sectional analysis. DNA samples were extracted from whole blood by standard lysis conditions and stored until analysis. Respective institutional review boards at each site approved the study protocol, and all subjects read and signed an informed consent document.

\section{Maximal isometric contraction test [maximal voluntary contraction (MVC)]}

MVC of the elbow flexors was tested at baseline on a specially designed and modified preacher bench using a strain gauge attached to a strength evaluation system (model 32628CTL; Lafayette Instrument Co., Lafayette, IN). Baseline isometric testing was performed over 3 days, separated by no more than $48 \mathrm{~h}$. The average of the $2 \mathrm{nd}$ and $3 \mathrm{rd}$ testing days was used as the baseline criterion measurement. Subjects were positioned with their arms at a $90^{\circ}$ angle at the medial epicondyle in line with the axis of rotation of the bench. Three tests lasting $3 \mathrm{~s}$ were performed on each arm, all separated by a 1-min rest period. The three peak force values were averaged for each testing day.

\section{One-repetition maximum (1RM) testing}

A 1-RM protocol as previously reported (Thompson et al. 2004) was used to measure dynamic strength of the elbow flexors on a standard preacher bench. Two warm-up sets were completed at 50 and $75 \%$ of the predicted 1RM for eight repetitions and five repetitions, respectively. Single attempts were performed until one single repetition with full-range of motion was completed, which was recorded and used for analysis.

\section{Volumetric measurements}

MRI was used to assess whole muscle, subcutaneous fat, and cortical bone volume of each arm. Baseline MRI scans 
were performed before or $48 \mathrm{~h}$ after any isometric or 1RM testing. Rapidia, a personal computer-based, three-dimensional, interactive system for viewing images from computerized tomography and MRI scans (3D Med Co. Ltd., Seoul, Republic of Korea), was used for all volumetric measurements. Six slices from each image were analyzed using the metaphyseal-diaphyseal junction landmark, making sure the same regions were measured from pre- and post-images. Cortical bone, subcutaneous fat, and muscle were isolated using image signal intensity differences between tissues, and once the region of interest was segmented, total volume was taken for the six evaluated slices. Repeatability and reliability of Rapidia volume measurements were verified using a phantom of known volume.

\section{Genotyping}

For FMS, blood samples were obtained from all individuals in EDTA anticoagulant, sent to the coordinating site in Washington, DC, without subject identification, and DNA was isolated using QIAGEN kits (QIAGEN, Valencia, CA). For Health ABC, Genomic DNA was extracted from the buffy coat layer of whole blood using the PURE-GENE DNA Purification Kit (Gentra System, Inc., Minneaapolis, $\mathrm{MN}, \mathrm{USA}$ ), and stored at $-80^{\circ} \mathrm{C}$ until analysis. Genotypes for the IGF1 -C1245T variant (rs35767) in this paper were obtained with the use of a TaqMan allelic discrimination assay that employs the $5^{\prime}$ nuclease activity of Taq polymerase to detect a fluorescent reporter (VIC and FAM) signal-generated during polymerase chain reactions (see Supplementary material). For this study, we use two methods of quality control for genotyping: the use of negative controls and genotyping of replicate samples (at least $5 \%$ of total). Replicate samples are checked and if there is not a match then the genotyping is repeated. Genotype analysis is performed using the latest version of the 7900HT Sequence Detection Software (SDS v2.3) and confirmed by manually by the technician.

\section{Statistical analyses}

For Health ABC, covariates collected at baseline, which are known correlates of muscle size and function were examined for associations with the phenotypic variables of interest by bivariate analysis (age, smoking history, physical activity, BMI, and reported disease (CAD, Cancer, COPD, Diabetes)). Statistically significant covariates were included in generalized linear regression models. Twelve size/strength phenotypes were analyzed as continuous quantitative traits (Table 2). Adjusted least square means were derived from a general linear model adjusting for age, smoking history, physical activity, BMI, and disease/ health status (as indicated above). Pair-wise linear tests comparing mean phenotype values among genotypes were conducted and resulting $P$-values were adjusted for multiple comparisons using the Sidak method. Analyses were conducted using Stata V9 (College Station, TX). Associations were considered to be statistically significant if the nominal $P$ value was less than 0.05 .

For FMS, due to the low percentage of participants representing other ethnic groups, all analyses were performed in whites, which accounted for $\sim 80 \%$ of the total study population. Four size/strength phenotypes were analyzed as continuous quantitative traits (Table 2). Normality of each quantitative trait was confirmed using the Shapiro-Wilk normality test. Bivariate analyses of each quantitative measurement showed several significant correlations with both age and baseline body mass; therefore, associations between IGFI and size/strength phenotypes were assessed using analysis of covariance methods. Due to large gender differences in baseline values, all analyses were performed separately for men and women, using generalized linear regression models which included age and/or baseline body mass as covariates. Adjusted least square means were derived from each model. Pair-wise linear tests comparing mean phenotype values among genotypes were conducted and resulting $P$ values were adjusted for multiple comparisons using the Sidak method. Analyses were conducted using Stata V9 (College Station, TX). Associations were considered to be statistically significant in the nominal $P$ value was less than 0.05 .

For both populations, the proportion of variance in muscle size/strength measurements attributable to IGFI genotype was determined by likelihood ratio tests comparing full (genotype and covariates) to constrained (covariates only) models. Hardy-Weinberg equilibrium was determined for IGFI SNP using a chi-square test to compare the observed genotype frequencies to those expected under Hardy-Weinberg equilibrium.

\section{Results}

Subject characteristics

A total of 2,999 subjects from the Health ABC study and 483 subjects from the FMS study were genotyped for the IGF1 promoter, rs35767 SNP. For the Health ABC study, 1,761 white and 1,238 black participants were genotyped. Participant's genotype data for rs35767 data are presented in Table 1. Allele and genotype frequencies did not differ significantly from Hardy-Weinberg expectations and were similar to those reported previously (Cheng et al. 2006; Hernandez et al. 2007). IGFI genotypes of Health ABC participants did not differ significantly by gender, but a significant difference did exist based on race $(P<0.001)$, 
Table 1 Participant characteristics of the Health, Ageing, and Body Composition (Health ABC) study and Functional Polymorphisms Associated with Human Muscle Size and Strength (FMS) study

\begin{tabular}{|c|c|c|c|c|c|c|c|c|c|c|}
\hline & \multicolumn{5}{|c|}{ Health $\mathrm{ABC}$} & \multicolumn{5}{|c|}{ FMS } \\
\hline & \multirow[t]{2}{*}{$N$} & \multirow[t]{2}{*}{ Age } & \multicolumn{3}{|c|}{ Genotype $(N)$} & \multirow[t]{2}{*}{$N$} & \multirow[t]{2}{*}{ Age (SD) } & \multicolumn{3}{|c|}{ Genotype $(N)$} \\
\hline & & & $\mathrm{CC}$ & $\mathrm{CT}$ & $\overline{\mathrm{TT}}$ & & & $\mathrm{CC}$ & $\mathrm{CT}$ & $\overline{\mathrm{TT}}$ \\
\hline \multicolumn{11}{|l|}{ Black } \\
\hline Male & 533 & $73.5(2.8)$ & 157 & 271 & 105 & - & - & - & - & - \\
\hline Female & 705 & $73.4(3.0)$ & 238 & 336 & 131 & - & - & - & - & - \\
\hline \multicolumn{11}{|l|}{ White } \\
\hline Male & 925 & 73.9 (2.8) & 621 & 279 & 25 & 184 & $23.8(5.8)$ & 123 & 47 & 14 \\
\hline Female & 836 & $73.6(2.8)$ & 567 & 238 & 31 & 299 & $24.1(5.8)$ & 170 & 96 & 33 \\
\hline
\end{tabular}

Age is mean years $(\mathrm{SD})$

though this was expected due to different allele frequencies between the populations. The black and white participants of Health $\mathrm{ABC}$ were not significantly different based on age or BMI. For the FMS cohort, 483 subjects were genotyped. At the time of analysis, the white ethnic grouping made up $\sim 80 \%$ of FMS participants; thus other ethnic groups did not allow realistic statistical comparisons to the phenotypes of interest. The average age of FMS subjects was 24 (SD 5.9) years and did not differ significantly between sexes. For rs35767 in the FMS cohort, genotype did not differ by sex but allele/genotype frequencies did differ from Hardy-Weinberg expectations $(P<0.0001)$.

\section{Genotype/phenotype association}

The primary association analysis conducted in the Health ABC study was 12 total phenotypes (Table 2) related to BC. Total number of subjects differed slightly for analysis purposes due to data that were unavailable for some subjects (Supplemental Table 1). The bivariate analyses between phenotypes and covariates (age, smoking, physical activity, and BMI) revealed significant positive associations $(P<0.01)$; thus phenotypes (Table 2$)$ were covaried for these variables in the final regression model. Disease status was not significant for every dependent variable but was included in the analysis model when significant. The covariate regression analysis revealed several significant associations in Black Females including lean mass, \% fat, muscle area, and BMD. Both lean mass and muscle area was lowest amongst the CC genotype group and significantly so when compared to the TT genotype group (2.7\%, $P<0.05$ and $3.1 \%, P<0.05$, respectively (Table 3 )). Additionally, BMD was significantly lower (4.8\%, $P<0.05)$ in the CC group compared to TT whilst $\%$ fat was highest in the CC group $(1.3 \%, P<0.05)$. In White Females from Health $\mathrm{ABC}$, trunk fat and total fat were highest in the CC genotype group $(2.6 \%, P<0.05$; and $2.0 \%, P<0.05$ respectively). White Males in the CC genotype group scored significantly lower in the single chair stand than those in the CT genotype group (4\%, $P<0.05)$ while Black Males showed no significant associations with any of the measured phenotypes and the IGFI polymorphism.

In the FMS cohort, only white females demonstrated a significant association with any phenotype, 1-RM was highest in the CT genotype group $(12 \%, P<0.05$ when compared to the CC genotype; and $18 \%, P<0.05$ when compared to TT (Table 3)). No other associations were found in the FMS cohort with the IGFI polymorphism. Table 3 emphasizes the positive associations found as all phenotypes in Table 2 were analyzed, yet only those listed in Table 3 were statistically significant.

\section{Discussion}

Here, we report the first association analysis of the $I G F 1$ promoter SNP rs35767 with body composition and muscle function. In two separate cohorts, the CC genotype of rs35767 was associated with phenotypes that may represent a reduced function of IGF1. Contrary to our original hypothesis, the majority of associations were not in muscle function, yet were consistent based on genotype. The association appears to be relevant specifically for older black and possibly white women. In the Health $\mathrm{ABC}$ cohort, rs35767 showed a significant association with measures of adipose tissue, BMD, and muscle, in black women. The CC genotype, in white women was associated with an increase in trunk fat and total body fat, and in black women with increased fat and decreased bone and muscle volume. In FMS, only white men and women were analyzed due to sample size. White women displayed reduced muscle strength with the CC or TT genotype with no other associations found in the FMS cohort. With the known biological function of $I G F 1$ and the change of IGFI that occurs with aging, it seems likely that the rs35767 SNP 
Table 2 Adjusted means of all variables separated by race, gender, and genotype

\begin{tabular}{|c|c|c|c|c|c|c|}
\hline \multirow[t]{2}{*}{ Phenotype } & \multicolumn{3}{|l|}{ White males genotype } & \multicolumn{3}{|c|}{ Black males genotype } \\
\hline & $\mathrm{CT}$ & CT & TT & $\mathrm{CC}$ & $\mathrm{CT}$ & TT \\
\hline Maximal isokinetic effort $(\mathrm{Nm})$ & $333.40 \pm 4.60$ & $338.80 \pm 6.65$ & $319.56 \pm 22.59$ & $313.96 \pm 10.49$ & $324.87 \pm 8.34$ & $297.92 \pm 13.31$ \\
\hline $20 \mathrm{~m}$ walk-time $(\mathrm{km} / \mathrm{s})$ & $.00016 \pm 1.8 \mathrm{e}-6 \quad 0.0$ & $.00016 \pm 2.7 \mathrm{e}-6 \quad 0$ & $0.00017 \pm 9.1 \mathrm{e}-6 \quad 0$. & $0.000019 \pm 2.9 \mathrm{e}-6$ & $0.00019 \pm 2.2 \mathrm{e}-6$ & $0.00019 \pm 3.6 \mathrm{e}-6$ \\
\hline Single chair stand (s) & $1.99 \pm 0.02$ & $2.07 \pm 0.03$ & $2.00 \pm 0.10$ & $2.13 \pm 0.07$ & $2.11 \pm 0.05$ & $2.15 \pm 0.09$ \\
\hline Grip strength $(\mathrm{kg})$ & $35.52 \pm 0.31$ & $35.37 \pm 0.46$ & $33.92 \pm 1.60$ & $38.87 \pm 0.74$ & $37.76 \pm 0.56$ & $37.45 \pm 0.92$ \\
\hline Trunk fat $(\mathrm{g})$ & $12779 \pm 85$ & $12781 \pm 127$ & $13159 \pm 445$ & $11056 \pm 178$ & $11136 \pm 139$ & $10966 \pm 222$ \\
\hline Trunk - lean + BMC $(\mathrm{g})$ & $28669 \pm 109$ & $28325 \pm 163$ & $28021 \pm 601$ & $27642 \pm 222$ & $27855 \pm 172$ & $27859 \pm 284$ \\
\hline Total fat $(\mathrm{g})$ & $23773 \pm 131$ & $23808 \pm 196$ & $23869 \pm 690$ & $22430 \pm 283$ & $22309 \pm 218$ & $22178 \pm 348$ \\
\hline Total lean + BMC (g) & $57588 \pm 207$ & $57020 \pm 307$ & $55855 \pm 1150$ & $58890 \pm 442$ & $59009 \pm 343$ & $59005 \pm 555$ \\
\hline Total percent fat & $28.68 \pm 0.13$ & $28.91 \pm 0.20$ & $29.32 \pm 0.75$ & $26.90 \pm 0.29$ & $26.84 \pm 0.22$ & $26.73 \pm 0.36$ \\
\hline $\begin{array}{l}\text { Thigh muscle area }\left(\mathrm{cm}^{2}\right)(2 \text { thigh } \\
\text { avg })\end{array}$ & $127.65 \pm 0.58$ & $126.68 \pm 0.87$ & $123.09 \pm 3.11$ & $138.89 \pm 1.41$ & $138.39 \pm 1.08$ & $137.90 \pm 1.74$ \\
\hline $\begin{array}{l}\text { Thigh muscle density (HU) (2 thigh } \\
\text { avg) }\end{array}$ & $37.59 \pm 0.22$ & $37.02 \pm 0.33$ & $36.43 \pm 1.19$ & $36.78 \pm 0.46$ & $37.22 \pm 0.35$ & $37.29 \pm 0.57$ \\
\hline \multirow{3}{*}{$\begin{array}{l}\text { Total hip bone mineral density } \\
\left(\mathrm{g} / \mathrm{cm}^{2}\right)\end{array}$} & $0.943 \pm 0.005$ & $0.941 \pm 0.008$ & $0.936 \pm 0.028$ & $1.00 \pm 0.01$ & $1.02 \pm 0.01$ & $1.03 \pm 0.01$ \\
\hline & \multicolumn{3}{|l|}{ White females } & \multicolumn{3}{|l|}{ Black females } \\
\hline & $\mathrm{CC}$ & $\mathrm{CT}$ & TT & $\mathrm{CC}$ & $\mathrm{CT}$ & TT \\
\hline Maximal isokinetic effort $(\mathrm{Nm})$ & $204.69 \pm 3.44$ & $213.23 \pm 5.35$ & $203.13 \pm 14.83$ & $208.15 \pm 5.12$ & $213.64 \pm 4.31$ & $206.92 \pm 7.15$ \\
\hline $20 \mathrm{~m}$ walk-time $(\mathrm{km} / \mathrm{s})$ & $0.00018 \pm 1.4 \mathrm{e}-6$ & $60.00018 \pm 2.2 \mathrm{e}-6$ & $-60.00017 \pm 6.1 \mathrm{e}-6$ & $0.00021 \pm 3.9 \mathrm{e}-6$ & $0.00021 \pm 3.2 \mathrm{e}-6$ & $0.00021 \pm 5.2 \mathrm{e}-6$ \\
\hline Single chair stand (s) & $2.12 \pm 0.03$ & $2.07 \pm 0.05$ & $1.98 \pm 0.15$ & $2.34 \pm 0.08$ & $2.17 \pm 0.07$ & $2.37 \pm 0.11$ \\
\hline Grip strength (kg) & $20.80 \pm 0.22$ & $20.58 \pm 0.34$ & $20.80 \pm 0.91$ & $22.48 \pm 0.41$ & $23.09 \pm 0.34$ & $23.00 \pm 0.56$ \\
\hline Trunk fat $(\mathrm{g})$ & $12512 \pm 87$ & $12197 \pm 133$ & $12332 \pm 380$ & $14203 \pm 158$ & $14410 \pm 133$ & $14083 \pm 214$ \\
\hline Trunk - lean + BMC (g) & $20298 \pm 87$ & $20093 \pm 132$ & $20260 \pm 377$ & $21343 \pm 153$ & $21421 \pm 127$ & $21838 \pm 204$ \\
\hline Total fat (g) & $26591 \pm 126$ & $26065 \pm 194$ & $26523 \pm 554$ & $31227 \pm 243$ & $30139 \pm 215$ & $30627 \pm 328$ \\
\hline Total lean + BMC (g) & $40035 \pm 159$ & $39504 \pm 242$ & $40268 \pm 682$ & $44169 \pm 296$ & $44348 \pm 247$ & $45379 \pm 398$ \\
\hline Total percent fat & $39.13 \pm 0.15$ & $38.97 \pm 0.23$ & $38.81 \pm 0.66$ & $40.44 \pm 0.25$ & $40.09 \pm 0.21$ & $39.15 \pm 0.33$ \\
\hline Thigh muscle area $\left(\mathrm{cm}^{2}\right)$ (2 thigh avg) & $85.14 \pm 0.45$ & $85.25 \pm 0.69$ & $87.04 \pm 1.96$ & $100.36 \pm 0.92$ & $100.75 \pm 0.77$ & $103.46 \pm 1.25$ \\
\hline Thigh muscle density (HU) (2 thigh avg) & $34.55 \pm 0.25$ & $35.03 \pm 0.39$ & $34.96 \pm 1.10$ & $31.87 \pm 0.42$ & $32.30 \pm 0.35$ & $33.11 \pm 0.57$ \\
\hline Total hip bone mineral density $\left(\mathrm{g} / \mathrm{cm}^{2}\right)$ & $0.86 \pm 0.01$ & $0.76 \pm 0.01$ & $0.78 \pm 0.02$ & $0.84 \pm 0.01$ & $0.86 \pm 0.01$ & $0.88 \pm 0.01$ \\
\hline \multirow[t]{3}{*}{ Phenotype } & \multicolumn{4}{|c|}{ White males } & & \\
\hline & \multicolumn{4}{|l|}{ Genotype } & & \\
\hline & \multicolumn{2}{|l|}{$\mathrm{CC}$} & $\mathrm{CT}$ & \multicolumn{2}{|l|}{ TT } & \\
\hline Baseline 1-RM strength (lbs) & \multicolumn{2}{|c|}{$26.40 \pm 0.52$} & $27.32 \pm 0.82$ & \multicolumn{2}{|c|}{$25.66 \pm 1.52$} & \\
\hline Baseline isometric strength (arm) (Nm) & \multicolumn{2}{|c|}{$144.89 \pm 4.03$} & $146.99 \pm 6.57$ & \multicolumn{2}{|c|}{$133.69 \pm 12.69$} & \\
\hline Baseline whole muscle volume $\left(\mathrm{cm}^{3}\right)$ & \multicolumn{2}{|c|}{$555100 \pm 11761$} & $573880 \pm 17936$ & \multicolumn{2}{|c|}{$495848 \pm 36206$} & \\
\hline \multirow[t]{3}{*}{ Baseline subQ fat volume $\left(\mathrm{cm}^{3}\right)$} & \multicolumn{2}{|c|}{$174204 \pm 7171$} & $171346 \pm 10935$ & \multicolumn{2}{|c|}{$175978 \pm 22075$} & \\
\hline & \multicolumn{3}{|c|}{ White females } & & & \\
\hline & \multicolumn{2}{|l|}{$\mathrm{CC}$} & $\mathrm{CT}$ & \multicolumn{2}{|l|}{$\mathrm{TT}$} & \\
\hline Baseline 1-RM strength (lbs) & \multicolumn{2}{|c|}{$13.60 \pm 0.28$} & $15.28 \pm 0.37$ & \multicolumn{2}{|c|}{$12.92 \pm 0.62$} & \\
\hline Baseline isometric strength (arm) (Nm) & $69.47 \pm 1$ & 1.95 & $68.36 \pm 2.62$ & $74.15 \pm 4.4$ & & \\
\hline Baseline whole muscle volume $\left(\mathrm{cm}^{3}\right)$ & $445296 \pm$ & $=11762$ & $448483 \pm 16785$ & $450800 \pm 31$ & 654 & \\
\hline Baseline subQ fat volume $\left(\mathrm{cm}^{3}\right)$ & $260511 \pm$ & 5779 & $255906 \pm 8246$ & $253311 \pm 15$ & 551 & \\
\hline
\end{tabular}

All means adjusted for age, smoking, $\mathrm{kcal} / \mathrm{kg} /$ week and BMI

All means adjusted for age and body mass 
Table 3 Significant findings of bivariate analysis comparing IGF1 genotype to phenotypes related to body composition and muscle function from Health $\mathrm{ABC}$ and $F M S$ studies

\begin{tabular}{|c|c|c|c|c|}
\hline \multirow[t]{2}{*}{ Health $\mathrm{ABC}$ phenotype $(F M S)$} & \multicolumn{3}{|l|}{ Genotype } & \multirow[t]{2}{*}{$P$} \\
\hline & $\mathrm{CC}$ & $\mathrm{CT}$ & $\mathrm{TT}$ & \\
\hline \multicolumn{5}{|l|}{ Black females } \\
\hline Total lean + BMC (g) & $44169 \pm 296$ & $44348 \pm 247$ & $45379 \pm 398$ & $0.007^{2}$ \\
\hline Total fat $(\%)$ & $40.4 \pm 0.3$ & $40.1 \pm 0.2$ & $39.1 \pm 0.3$ & $0.035^{1}, 0.035^{2}$ \\
\hline Thigh muscle area $\left(\mathrm{cm}^{2}\right)$ & $100.4 \pm .9$ & $100.8 \pm .8$ & $103.5 \pm 1.3$ & $0.040^{1}, 0.008^{2}$ \\
\hline Total hip BMD $\left(\mathrm{g} / \mathrm{cm}^{2}\right)$ & $0.84 \pm 0.008$ & $0.86 \pm 0.007$ & $0.88 \pm 0.011$ & $0.004^{1}$ \\
\hline \multicolumn{5}{|l|}{ White females } \\
\hline Trunk fat $(\mathrm{g})$ & $12512 \pm 87$ & $12197 \pm 134$ & $12332 \pm 380$ & $0.048^{3}$ \\
\hline Total fat (g) & $26591 \pm 126$ & $26065 \pm 194$ & $26523 \pm 554$ & $0.017^{3}$ \\
\hline $1-R M(l b)$ & $13.6 \pm 0.3$ & $15.28 \pm 0.04$ & $12.9 \pm 0.62$ & $0.009^{3}, 0.0036^{2}$ \\
\hline \multicolumn{5}{|l|}{ White males } \\
\hline Single chair stand (s) & $1.99 \pm 0.02$ & $2.07 \pm 0.03$ & $2.00 \pm 0.10$ & $0.023^{3}$ \\
\hline \multicolumn{5}{|l|}{ Black males } \\
\hline- & - & - & - & NS \\
\hline
\end{tabular}

Values are means adjusted for age, smoking history, total physical activity, BMI, and disease status (FMS adjusted for age and body mass)

3 CC significantly different than CT

2 CT significantly different than TT

1 CC significantly different than TT

NS No significant differences between genotypes

could explain some of the variability in these phenotypes that occurs with aging, specifically in black women.

IGFI is known to be necessary and sufficient in promoting muscle growth and development. Indeed, knockout models have demonstrated the lack of $I G F 1$ causing severe lack of muscle development (Powell-Braxton et al. 1993). Muscle-specific overexpression of IGFI causes muscle hypertrophy, and human studies report an increase in IGF1 in response to hypertrophy stimulating exercise (Coleman et al. 1995; Gonzalez et al. 2003; Greig et al. 2006; Bamman et al. 2007). In the search for target SNPs or genes related to $\mathrm{BC}$ and muscle function, IGFl is a likely target based on its known function. Additionally, in the only studies to use genome wide linkage to identify areas that may be influencing differences in muscle between individuals, the $I G F 1$ locus has been consistently identified as one of the most likely targets (Sun et al. 1999; Chagnon et al. 2001). The known loss of muscle that occurs with aging coinciding with decreasing levels of IGF1 with aging, makes the IGFI promoter region an especially promising target for study as it relates to aging and BC. Indeed, numerous studies have examined the $I G F 1$ promoter in the context of diseases that may be controlled by IGFI expression (Cheng et al. 2006; Tamimi et al. 2007; Hernandez et al. 2007). Our current data suggest that this polymorphism may have a functional component. Yet based on genotype, we only report a small difference in muscle function in young white women and a difference in muscle size in older black women.
In a preliminary analysis of our data, it was suggested that the rs35767 SNP was associated with muscle function (Devaney et al. 2004). Our current data support the hypothesis that a polymorphism in this gene may affect phenotypes that are dependent upon $I G F 1$ function, at least in older black women. Polymorphisms in the IGFI promoter, being previously examined, have been associated with similar phenotypes to the current study that are under at least some control of IGFI (Cheng et al. 2006; Canzian et al. 2006; Tamimi et al. 2007). The rs35767 SNP has been associated with circulating levels of IGF1 (Canzian et al. 2006; Palles et al. 2008). This variant is located in a region that is conserved at $>70 \%$ sequence identity between human, dog, mouse, and rat. In addition, this variant is predicted to disrupt a transcription factor binding site based on our analysis (Conde et al. 2006). Therefore, we predict that the $\mathrm{C}$ allele (or in this case the $\mathrm{CC}$ genotype) of rs35767 is associated with lower levels of IGF1 in skeletal muscle, potentially leading to greater amounts of adipose tissue and less skeletal muscle mass with aging.

The most applied or clinically relevant finding in the current study is the almost exclusive association of rs35767 and BC phenotypes in older women, primarily black women. Both men and women exhibit a decreased level of circulating IGF1 with aging (Velasco et al. 1998; Baumgartner et al. 1999). This decrease in IGF1 correlates with the increase in adiposity and loss of muscle and bone mass in men and women with increasing age. 
However, these changes in body composition are more clinically relevant in women leading to diseases such as osteoporosis, sarcopenia, and diabetes, as women are more susceptible to these diseases. Thus, any variability in the aforementioned $\mathrm{BC}$ phenotypes or genotypes that could affect these phenotypes would be of importance for aging women. A critical point in data interpretation is that all significant associations found are in agreement; the CC genotype is representative of reduced $I G F I$ function, specifically in women. Admittedly, the experimental design of the current study could allow false associations by analyzing numerous phenotypes. Data interpretation would be difficult if SNP function differed based on race, sex, or even a particular phenotype. Yet, when all phenotypes were analyzed, Table 3 shows that all associations agree that the lowest IGF1 function occurs in the $\mathrm{CC}$ genotype. The one exception is a higher 1RM for the CT genotype in the FMS cohort, which might be an age effect. Regardless, our results indicate seven total associations in women with all seven representing reduced $I G F 1$ function with the CC genotype and six of seven being in older women.

In interpreting our results, we note the FMS cohort's inconsistency with Hardy-Weinberg equilibrium. Considering our rigorous genotyping controls and validation, the most likely explanation is a selection bias in recruitment for the FMS study. Willingness to be involved in a strength training study whose primary purpose was to uncover polymorphisms associated with the response to strength training could cause a selection bias based on an individual's self-perception and the nature of the study. As the standard error of the female heterozygotes is very low, it is unlikely that one or two participants skewed the results. Additionally, the $7 \%$ less than expected number of heterozygotes was identical between male and female participants in FMS. Therefore, we believe a selection bias may have occurred which could increase the likelihood of type I error though it seems unlikely in this case due to the consistency of our findings.

Given the current findings of the $\mathrm{CC}$ genotype associating with phenotypes that reflect reduced function of $I G F 1$, we reexamined the data using a dominant model and the CC genotype. The only difference from our original results was a finding of reduced BMD in black males with the CC genotype and the loss of a statistically significant association of black females with muscle volume and lean mass, with all other variables remaining statistically significant. These findings lend support to the hypothesis that the $\mathrm{CC}$ genotype is associated with reduced $I G F 1$ function; yet, in black women these results suggest that the metabolic effects of reduced $I G F 1$ function drive the association of fat mass and rs35767. And while direct data comparisons are difficult due to covariance adjustments in our and others data sets, our strength data and genotype data are consistent with previous studies in relative differences between men and women, old and young, and the overall effect of the genotype of one gene (Lynch et al. 1999; Pescatello et al. 2006; Odden et al. 2006). Our results of an association of rs35767 with phenotypes affected by IGF1 and aging appear consistent with additional recent reports in women (Canzian et al. 2006; Tamimi et al. 2007). While, it is possible that another polymorphism in LD could explain some of these findings, our current data provide a starting point that can be used for future haplotype analysis in $I G F 1$.

An interpretation of applied functional outcomes is speculative; however, disease susceptibility or predictability may be the most important use of association studies. Differences in total lean mass and muscle mass were approximately $3 \%$ greater in the TT genotype group (black women) when compared to $\mathrm{CC}$ which would be consistent with the loss of muscle that would occur due to 3-4 years of aging in the elderly (Lindle et al. 1997). This small difference is likely to contribute to an even larger percentage difference in muscular strength/function (Reid et al. 2008), and in long term, could result in differences in physical function and also resting metabolism, obesity, $\mathrm{CAD}$, diabetes, or CVD. As for BMD, the differences are substantial, a 5\% greater BMD in the TT genotype group as compared to CC. To interpret, a meta-analysis of 15 clinical trials of calcium supplementation reported only $2.1 \%$ increase in BMD, which results in a $23 \%$ reduction in vertebral fracture risk (Shea et al. 2002), while a study of 36,282 women over 7 years that examined 1,000 $\mathrm{mg}$ of $\mathrm{Ca}$ and 400 IU of Vitamin D3 found a 1.06\% increase in BMD and a $29 \%$ reduction in hip fracture risk among adherent subjects (Jackson et al. 2006). Thus the 5\% difference found in the current study could have a substantial impact on osteoporosis and bone health. A potential application of the current findings is in preventative medicine, as susceptible women could be identified and interventions begun sooner.

In conclusion, the current findings appear to indicate a reduced function of $I G F 1$ in older women associated with the $\mathrm{C}$ allele of rs35767; while most specific to systemic IGF1 function (BMD, fat, and muscle), is the association in older black women. To be able to predict health and quality of life changes with age in a specific population is important in public health and on an individual basis. Future studies should target these populations (i.e. women, specifically black women) to confirm these findings. Furthermore, studies analyzing the functionality of this and/or other nearby SNPs is needed before definitive recommendations can be made based on genotype. Additionally, future haplotype studies are needed and should be conducted in various ethnic backgrounds. 
Acknowledgments This research was supported in part by the Intramural Research Program of the NIH, National Institute on Aging (NIA contract numbers: N01-AG-6-2101, N01-AG-6-2103, N01-AG6-2106).

Open Access This article is distributed under the terms of the Creative Commons Attribution Noncommercial License which permits any noncommercial use, distribution, and reproduction in any medium, provided the original author(s) and source are credited.

\section{References}

Atkinson HH, Rosano C, Simonsick EM, Williamson JD, Davis C, Ambrosius WT, Rapp SR, Cesari M, Newman AB, Harris TB, Rubin SM, Yaffe K, Satterfield S, Kritchevsky SB (2007) Cognitive function, gait speed decline, and comorbidities: the health, aging and body composition study. J Gerontol A Biol Sci Med Sci 62(8):844-850

Bamman MM, Petrella JK, Kim JS, Mayhew DL, Cross JM (2007) Cluster analysis tests the importance of myogenic gene expression during myofiber hypertrophy in humans. J Appl Physiol 102(6):2232-2239

Baumgartner RN, Waters DL, Gallagher D, Morley JE, Garry PJ (1999) Predictors of skeletal muscle mass in elderly men and women. Mech Ageing Dev 107(2):123-136

Brach JS, Simonsick EM, Kritchevsky S, Yaffe K, Newman AB (2004) The association between physical function and lifestyle activity and exercise in the health, aging and body composition study. J Am Geriatr Soc 52(4):502-509

Canzian F, McKay JD, Cleveland RJ, Dossus L, Biessy C, Rinaldi S, Landi S, Boillot C, Monnier S, Chajes V, Clavel-Chapelon F, Tehard B, Chang-Claude J, Linseisen J, Lahmann PH, Pischon T, Trichopoulos D, Trichopoulou A, Zilis D, Palli D, Tumino R, Vineis P, Berrino F, Bueno-de-Mesquita HB, van Gils $\mathrm{CH}$, Peeters PH, Pera G, Ardanaz E, Chirlaque MD, Quiros JR, Larranaga N, Martinez-Garcia C, Allen NE, Key TJ, Bingham SA, Khaw KT, Slimani N, Norat T, Riboli E, Kaaks R (2006) Polymorphisms of genes coding for insulin-like growth factor 1 and its major binding proteins, circulating levels of IGF-I and IGFBP-3 and breast cancer risk: results from the EPIC study. Br J Cancer 94(2):299-307

Chagnon YC, Rice T, Perusse L, Borecki IB, Ho-Kim MA, Lacaille M, Pare C, Bouchard L, Gagnon J, Leon AS, Skinner JS, Wilmore JH, Rao DC, Bouchard C (2001) Genomic scan for genes affecting body composition before and after training in Caucasians from HERITAGE. J Appl Physiol 90(5):1777-1787

Cheng I, Stram DO, Penney KL, Pike M, Le Marchand L, Kolonel LN, Hirschhorn J, Altshuler D, Henderson BE, Freedman ML (2006) Common genetic variation in IGF1 and prostate cancer risk in the Multiethnic Cohort. J Natl Cancer Inst 98(2):123-134

Coleman ME, DeMayo F, Yin KC, Lee HM, Geske R, Montgomery C, Schwartz RJ (1995) Myogenic vector expression of insulinlike growth factor I stimulates muscle cell differentiation and myofiber hypertrophy in transgenic mice. J Biol Chem 270(20):12109-12116

Conde L, Vaquerizas JM, Dopazo H, Arbiza L, Reumers J, Rousseau F, Schymkowitz J, Dopazo J (2006) PupaSuite: finding functional single nucleotide polymorphisms for large-scale genotyping purposes. Nucleic Acids Res 34(Web Server Issue):W621-W625

Devaney JM, Harmon B, Thompson P, Moyna N, Seip R, Price T, Clarkson P, Angelopoulous T, Gordish HH, Eric P (2004) Novel genetic variation in muscle genes correlated with muscle strength, size and response to resistance training (FAMuSS). American College of Sports Medicine, Annual Meeting. San Francisco, CA

Frayling TM, Hattersley AT, McCarthy A, Holly J, Mitchell SM, Gloyn AL, Owen K, Davies D, Smith GD, Ben-Shlomo Y (2002) A putative functional polymorphism in the IGF-I gene: association studies with type 2 diabetes, adult height, glucose tolerance, and fetal growth in U.K. populations. Diabetes 51(7):2313-2316

Gonzalez E, Messi ML, Zheng Z, Delbono O (2003) Insulin-like growth factor-1 prevents age-related decrease in specific force and intracellular $\mathrm{Ca} 2+$ in single intact muscle fibres from transgenic mice. J Physiol 552(Pt 3):833-844

Goodpaster BH, Carlson CL, Visser M, Kelley DE, Scherzinger A, Harris TB, Stamm E, Newman AB (2001) Attenuation of skeletal muscle and strength in the elderly: The Health $\mathrm{ABC}$ Study. J Appl Physiol 90(6):2157-2165

Greig CA, Hameed M, Young A, Goldspink G, Noble B (2006) Skeletal muscle IGF-I isoform expression in healthy women after isometric exercise. Growth Horm IGF Res 16(5-6):373376

Hand BD, Kostek MC, Ferrell RE, Delmonico MJ, Douglass LW, Roth SM, Hagberg JM, Hurley BF (2007) Influence of promoter region variants of insulin-like growth factor pathway genes on the strength-training response of muscle phenotypes in older adults. J Appl Physiol 103(5):1678-1687

Hernandez W, Grenade C, Santos ER, Bonilla C, Ahaghotu C, Kittles RA (2007) IGF-1 and IGFBP-3 gene variants influence on serum levels and prostate cancer risk in African-Americans. Carcinogenesis 28(10):2154-2159

Jackson RD, LaCroix AZ, Gass M, Wallace RB, Robbins J, Lewis CE, Bassford T, Beresford SA, Black HR, Blanchette P, Bonds DE, Brunner RL, Brzyski RG, Caan B, Cauley JA, Chlebowski RT, Cummings SR, Granek I, Hays J, Heiss G, Hendrix SL, Howard BV, Hsia J, Hubbell FA, Johnson KC, Judd H, Kotchen JM, Kuller LH, Langer RD, Lasser NL, Limacher MC, Ludlam S, Manson JE, Margolis KL, McGowan J, Ockene JK, O’Sullivan MJ, Phillips L, Prentice RL, Sarto GE, Stefanick ML, Van Horn L, Wactawski-Wende J, Whitlock E, Anderson GL, Assaf AR, Barad D (2006) Calcium plus vitamin D supplementation and the risk of fractures. $\mathrm{N}$ Engl $\mathrm{J}$ Med 354(7):669-683

Kim JG, Roh KR, Lee JY (2002) The relationship among serum insulin-like growth factor-I, insulin-like growth factor-I gene polymorphism, and bone mineral density in postmenopausal women in Korea. Am J Obstet Gynecol 186(3):345-350

Kostek MC, Delmonico MJ, Reichel JB, Roth SM, Douglass L, Ferrell RE, Hurley BF (2005) Muscle strength response to strength training is influenced by insulin-like growth factor 1 genotype in older adults. J Appl Physiol 98(6):2147-2154

Lindle RS, Metter EJ, Lynch NA, Fleg JL, Fozard JL, Tobin J, Roy TA, Hurley BF (1997) Age and gender comparisons of muscle strength in 654 women and men aged 20-93 yr. J Appl Physiol 83(5):1581-1587

Lynch NA, Metter EJ, Lindle RS, Fozard JL, Tobin JD, Roy TA, Fleg JL, Hurley BF (1999) Muscle quality. I. Age-associated differences between arm and leg muscle groups. J Appl Physiol 86(1):188-194

Missmer SA, Haiman CA, Hunter DJ, Willett WC, Colditz GA, Speizer FE, Pollak MN, Hankinson SE (2002) A sequence repeat in the insulin-like growth factor-1 gene and risk of breast cancer. Int J Cancer 100(3):332-336

Odden MC, Chertow GM, Fried LF, Newman AB, Connelly S, Angleman S, Harris TB, Simonsick EM, Shlipak MG (2006) Cystatin $\mathrm{C}$ and measures of physical function in elderly adults: 
the Health, Aging, and Body Composition (HABC) Study. Am J Epidemiol 164(12):1180-1189

Palles C, Johnson N, Coupland B, Taylor C, Carvajal J, Holly J, Fentiman IS, Dos Santos Silva I, Ashworth A, Peto J, Fletcher O (2008) Identification of genetic variants that influence circulating IGF1 levels: a targeted search strategy. Hum Mol Gene 17:14571464

Park SW, Goodpaster BH, Strotmeyer ES, de Rekeneire N, Harris TB, Schwartz AV, Tylavsky FA, Newman AB (2006) Decreased muscle strength and quality in older adults with type 2 diabetes: the health, aging, and body composition study. Diabetes 55(6): 1813-1818

Pescatello LS, Kostek MA, Gordish-Dressman H, Thompson PD, Seip RL, Price TB, Angelopoulos TJ, Clarkson PM, Gordon PM, Moyna NM, Visich PS, Zoeller RF, Devaney JM, Hoffman EP (2006) ACE ID genotype and the muscle strength and size response to unilateral resistance training. Med Sci Sports Exerc 38(6):1074-1081

Powell-Braxton L, Hollingshead P, Warburton C, Dowd M, PittsMeek S, Dalton D, Gillett N, Stewart TA (1993) IGF-I is required for normal embryonic growth in mice. Genes Dev 7(12B):2609-2617

Reid KF, Naumova EN, Carabello RJ, Phillips EM, Fielding RA (2008) Lower extremity muscle mass predicts functional performance in mobility-limited elders. J Nutr Health Aging 12(7):493-498

Rietveld I, Janssen JA, Hofman A, Pols HA, van Duijn CM, Lamberts SW (2003) A polymorphism in the IGF-I gene influences the age-related decline in circulating total IGF-I levels. Eur J Endocrinol 148(2):171-175

Rosen CJ, Kurland ES, Vereault D, Adler RA, Rackoff PJ, Craig WY, Witte S, Rogers J, Bilezikian JP (1998) Association between serum insulin growth factor-I (IGF-I) and a simple sequence repeat in IGF-I gene: implications for genetic studies of bone mineral density. J Clin Endocrinol Metab 83(7):2286-2290

Shea B, Wells G, Cranney A, Zytaruk N, Robinson V, Griffith L, Ortiz Z, Peterson J, Adachi J, Tugwell P, Guyatt G (2002) Metaanalyses of therapies for postmenopausal osteoporosis. VII.
Meta-analysis of calcium supplementation for the prevention of postmenopausal osteoporosis. Endocr Rev 23(4):552-559

Sun G, Gagnon J, Chagnon YC, Perusse L, Despres JP, Leon AS, Wilmore JH, Skinner JS, Borecki I, Rao DC, Bouchard C (1999) Association and linkage between an insulin-like growth factor-1 gene polymorphism and fat free mass in the HERITAGE Family Study. Int J Obes Relat Metab Disord 23(9):929-935

Taaffe DR, Harris TB, Ferrucci L, Rowe J, Seeman TE (2000) Crosssectional and prospective relationships of interleukin-6 and C-reactive protein with physical performance in elderly persons: MacArthur studies of successful aging. J Gerontol A Biol Sci Med Sci 55(12):M709-M715

Tamimi RM, Cox DG, Kraft P, Pollak MN, Haiman CA, Cheng I, Freedman ML, Hankinson SE, Hunter DJ, Colditz GA (2007) Common genetic variation in IGF1, IGFBP-1, and IGFBP-3 in relation to mammographic density: a cross-sectional study. Breast Cancer Res 9(1):R18

Thompson PD, Moyna N, Seip R, Price T, Clarkson P, Angelopoulos T, Gordon P, Pescatello L, Visich P, Zoeller R, Devaney JM, Gordish H, Bilbie S, Hoffman EP (2004) Functional polymorphisms associated with human muscle size and strength. Med Sci Sports Exerc 36(7):1132-1139

Velasco B, Cacicedo L, Escalada J, Lopez-Fernandez J, SanchezFranco F (1998) Growth hormone gene expression and secretion in aging rats is age dependent and not age-associated weight increase related. Endocrinology 139(3):1314-1320

Visser M, Fuerst T, Lang T, Salamone L, Harris TB (1999) Validity of fan-beam dual-energy X-ray absorptiometry for measuring fat-free mass and leg muscle mass. Health, Aging, and Body Composition Study-Dual-Energy X-ray Absorptiometry and Body Composition Working Group. J Appl Physiol 87(4): $1513-1520$

Visser M, Pahor M, Tylavsky F, Kritchevsky SB, Cauley JA, Newman AB, Blunt BA, Harris TB (2003) One- and two-year change in body composition as measured by DXA in a population-based cohort of older men and women. J Appl Physiol 94(6):2368-2374 